
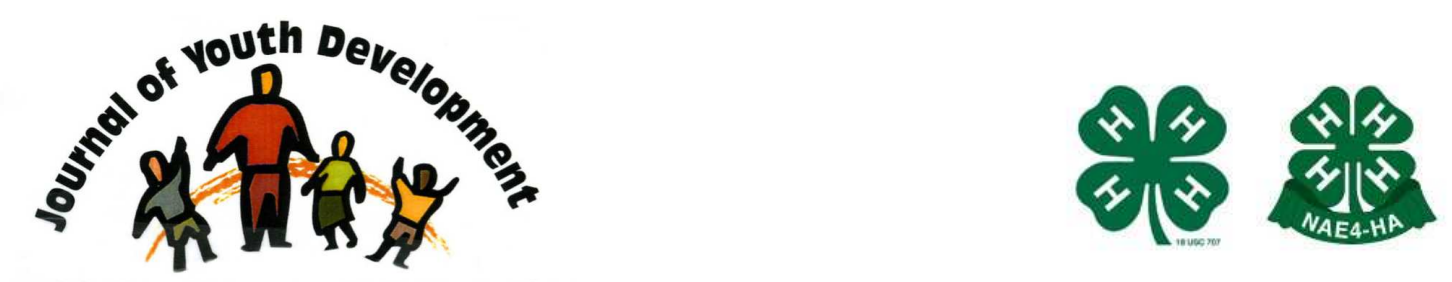

Bridging Research \& Practice

\title{
Youth Assets and Sexual Activity Among Hispanic Youth
}

\author{
Sharon Rodine \\ Oklahoma institute for Child Advocacy \\ srodine@oica.org \\ Roy F. Oman \\ University of Oklahoma Health Sciences Center \\ Roy-Oman@ouhsc.edu \\ Eleni Tolma \\ University of Oklahoma Health Sciences Center \\ Eleni-Tolma@ouhsc.edu \\ Cheryl B. Aspy \\ University of Oklahoma Health Sciences Center \\ Cheryl-Aspy@ouhsc.edu \\ Sara K. Vesely \\ University of Oklahoma Health Sciences Center \\ Sara-Vesely@ouhsc.edu \\ LaDonna Marshall \\ Oklahoma institute for Child Advocacy \\ Imarshall@oica.org \\ Janene Fluhr \\ University of Oklahoma Health Sciences Center \\ Janene-Fluhr@ouhsc.edu
}




\title{
JOURNAL OF YOUTH DEVELOPMENT \\ bridging research and practice

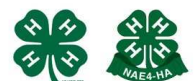

Bridging Research \& Practice

Volume 3, Number 1, Summer 2008

Article 080301FA004

\section{Youth Assets and Sexual Activity Among Hispanic Youth}

\author{
Sharon Rodine and La Donna Marshall \\ Oklahoma Institute for Child Advocacy \\ Roy F. Oman, Eleni Tolma, Cheryl B. Aspy, Sara K. Vesely and Janene Fluhr
University of Oklahoma Health Sciences Center
}

\begin{abstract}
Hispanic females, ages 15-19, experienced the highest birth rates and smallest decline in birth rates over the past decade compared to youth of other racial/ethnic groups. This study's purpose was to investigate relationships among a series of protective factors, or youth assets, and sexual activity in the Hispanic/Latino youth population. Data were collected from Hispanic youth and their parents ( $\mathrm{N}=232$ youth/parent pairs) in randomly selected households using in-person, in-home interview methods. Independent variables were nine youth assets; "never had sexual intercourse" was the dependent variable. Data were analyzed using logistic regression analysis. Three assets were found to be significantly associated with whether or not Hispanic/Latino youth ever had sexual intercourse. Odds of never having had sexual intercourse were at least three times higher for youth with the Peer Role Models, Use of Time (religion), or Responsible Choices assets, compared to youth without these assets. Further Hispanic youth asset/risk behavior research is merited.
\end{abstract}

\section{Purpose}

Birth rates for teens of all racial and ethnic groups have reached an all-time low in the U.S., marking a steady decline in the teen birth rate since its most recent peak in 1991 (Hamilton, Martin, \& Sutton, 2003). Compared to the overall teen population, Hispanic/Latino teens experienced the highest birth rates and the smallest decline in these rates among all racial and ethnic groups during the past decade (Ryan, Franzetta, \& Manlove, 2005). 
The birth rate for Hispanic teens has been the highest among all racial and ethnic groups since 1995, actually increasing slightly between 2003 and 2004 (Martin et al., 2005). The birth rate per 1,000 Hispanic females aged 15-19 was twice as high as the birth rate among the general female population of the same age group, according to preliminary 2004 data (Hamilton, Ventura, Martin, \& Sutton, 2005).

Over half of sexually experienced Hispanic teen females (52\%) have been pregnant, compared to $40 \%$ of sexually experienced non-Hispanic African American teens females and $23 \%$ of sexually experienced non-Hispanic white teen females, according to findings from the National Survey of Family Growth (National Campaign to Prevent Teen Pregnancy, 2006). According to the same survey, the percentage of sexually experienced Hispanic teen males (aged 15-19) who have ever been involved in a pregnancy was $21 \%$, compared to $19 \%$ for non-Hispanic African American teen males and 9\% for non-Hispanic white teen males (National Campaign to Prevent Teen Pregnancy, 2006).

Higher rates of sexual activity and lower rates of contraceptive use are reported for Hispanic youth compared to the general teen population, which puts them at increased risk not only for pregnancy, but also for sexually transmitted diseases (STDs) and Human Immunodeficiency Virus/Acquired Immunodeficiency Syndrome (HIV/AIDS) (Ryan et al., 2005). The disproportionate risk for HIV infection among Hispanic youth, is reflected in the higher percentages of HIV and AIDS cases than their percentage of the population (Centers for Disease Control and Prevention, 2001; U. S. Census Bureau, 2002).

Accompanying the high teen birth rates is the fact that the Hispanic population is the largest minority group and the fastest-growing major racial/ethnic group in the United States (U. S. Census Bureau, 2001). Between 2000 and 2010, the overall Hispanic population is projected to grow by one-third (34\%) -- almost four times faster than that of the total U.S. population (U.S. Census Bureau, 2004). The growth of the Hispanic teen population is expected to be even more dramatic over the next 20 years (U.S. Census Bureau, 2004). During that period, it is estimated that the number of Latino teens will grow by 50 percent, while the total teen population will grow by only six percent (Ryan et al., 2005). By the year 2020, one in five teens in the U.S. will be Hispanic (Day, 1996).

Parents of Hispanic youth have lower levels of education than those of other young people, and they have made little economic progress over the years (Driscoll, Brindis, Biggs, \& Valderrama, 2004). Both of these factors - families with low levels of education and low incomes -- are associated with greater sexual risk-taking among young people (Driscoll et al., 2004). Also heightening the risks associated with sexual activity among Hispanic youth are language challenges, a lack of access to health care and health insurance, low levels of accurate and timely information about HIV and STIs, and a lack of access to and use of contraception (Driscoll et al., 2004). Research shows that the importance of peer influences increases during adolescence for all teens. Hispanic teens tend to overestimate the proportion of their peers that are sexually active, thus what they perceive their peers' behavior and attitudes to be may be reflected in their behavior (Driscoll, Biggs, Brindis, \& Yankah, 2001).

A review of the literature suggests the importance of family characteristics in relation to early sexual activity by Hispanic youth. These characteristics include parental supervision/monitoring, discipline, parental support, and family structure. Associations with significant adults may have a strong influence on adolescents' decisions about sex and pregnancy issues (Moore, Peterson, 
\& Furstenberg, 1986). This highlights the potential efficacy of family influences on the postponement of adolescents' initiation of sexual activity (Moore et al., 1986).

Research conducted by (Longmore, Manning, \& Giordano, 2001) examined the effect of parenting strategies such as support, coercive control, and monitoring on the eventual initiation of sexual intercourse. The authors found that children who are monitored by their parents delay onset of sexual activity. Conversely, parental support and coercive control did not influence the timing of sexual initiation (Longmore et al., 2001).

Another study concluded that family structure, parent sexual behavior, and modeling of peers were closely associated with adolescent sexual attitudes and behaviors (Rucibwa, Modeste, Montgomery, \& Fox, 2003). Teens whose parents have permissive attitudes about sex and who have friends who are sexually active are more likely to have sexual intercourse. Other research supports the association of parental supervision with a reduction in adolescent sexual activity (Velez-Pastrana, Gonzalez-Rodriguez, \& Borges-Hernandez, 2005).

Noting they are a relatively new area of inquiry, researchers studying health risk behaviors among Hispanic youth have begun to identify youth development strategies as potentially effective ways to reduce adolescent health risk behaviors (Rodriguez \& Morrobel, 2004). Along with a call for incorporating research-based youth development strategies as part of overall prevention efforts, both researchers and practitioners have begun to focus on the need for a greater understanding of how those strategies might be protective in influencing sexual and reproductive health and behavior of Latino youth (Driscoll et al., 2001).

When trying to improve health outcomes among youth, research suggests that focusing solely on "fixing problems" is no longer enough. A range of positive services, supports, and opportunities that help young people build specific capabilities, competencies, skills, and positive qualities need to be at the core of prevention and development strategies (Pittman, Irby, Tolman, Yohalem, \& Feber, 2003). These positive youth development strategies reflect a shift in recent years from a traditional, deficit-based approach focused primarily on the problem behavior, to an approach based on the belief that all young people have strengths to be nurtured and that young people can become contributing participants in their families and communities (Leffert et al., 1998).

Numerous studies suggest that prevention efforts to reduce sexual risk-taking among youth may be strengthened by incorporating youth development strategies to increase protective factors, or youth assets, which appear to help insulate young people from engaging in harmful behaviors (Benard, 1990; Bogenschneider, 1996; Jessor, 1991; Kirby et al., 1994; McKnight, 1997; Scales, 1990). An extensive review of 19 youth development programs (Catalano, Berglund, Ryan, Lonczak, \& Hawkins, 1998) reported significant improvements in positive youth behaviors such as interpersonal skills, quality of adult and peer relationships, self-control, problem solving, cognitive competencies, self-efficacy, commitment to schooling, and academic achievement.

Studies have found that youth with these assets are less likely to participate in risk behaviors. For example, studies have shown that teens that are performing well in school and who have career plan are less likely to become pregnant and that teens in families with high levels of cohesion or parental monitoring are less likely to engage in sexual risk behavior (Beal, Ausiello, \& Perrin, 2001; DiIorio, Kelley, \& Hockenberry-Eaton, 1999; Kirby, 2001; Resnick et al., 1997; Scales \& Leffert, 1999) Another study, involving the entire population of the present study, 
found that specific youth assets (i.e., Non-Parental Adult Role Models, Peer Role Models, Use of Time (religion) and Aspirations for the Future) were each independently and significantly related to youth never having had participated in sexual intercourse (Vesely et al., 2004).

Despite the high rates of sexual activity, pregnancy, and births among Hispanic youth, a search of the literature found little research that focused on specific factors, or youth assets, that may protect Hispanic/Latino youth from participating in sexual risk behaviors. This study is among the first to investigate potential associations between youth assets and sexual intercourse among Hispanic youth. The findings from this study will inform program and policy development efforts that seek to reach Hispanic teens with effective, culturally appropriate teen pregnancy prevention strategies that incorporate a strength-based, youth development approach.

\section{Methods}

Data were collected for a larger study conducted through the HEART of OKC (Healthy, Empowered And Responsible Teens of Oklahoma City), a community-based project funded by the Centers for Disease Control and Prevention (CDC) as part of a national teen pregnancy prevention initiative. The primary objective of the project was to promote teen pregnancy prevention from a perspective of blending risk-reduction with youth development strategies. The approach focused on building youth assets while simultaneously working to reduce sexual risk-taking and related adolescent health risk behaviors, instead of addressing teen pregnancy as a single, isolated, free-standing issue.

One parent and one adolescent ( $N=1350$ youth/parent pairs) from randomly selected households in inner-city areas of two Oklahoma cities participated in interviews that were conducted in the respondents' homes using a computer-assisted data entry system (Oman, McLeroy, et al., 2002a). The adolescent and parent were interviewed at the same time, but in different rooms of the residence. The teenager self-administered the risk behavior questionnaire by listening to tape recorded items with headphones and then entering responses into the computer. Findings reported in this article reflect the interviews of 232 Hispanic youth, equally divided between males and females. The response rate was $51 \%$, which included all youth who refused to participate in the study plus a percentage $(8 \%)$ of the households for which study staff were never able to determine if a youth lived in the household.

\section{Measures}

Demographic, asset and sexual activity data were collected from adolescent respondents. Household income, family structure, and parent education data were collected from parent respondents.

\section{Youth assets}

Specific youth assets were the independent variables in this study. Focus groups and needs assessment data were used to determine the key assets. A literature search was conducted to identify appropriate items for asset measurement. Items with established reliability and validity from previously published research were used when possible. Items were created and pretested if appropriate items were not available in the literature.

Nine youth assets (shown in Table 2) were identified and measures developed for each following a lengthy period of focus group and pilot testing. Factor analyses and reliability testing 
determined items included in the final asset scales (Oman, Vesely, et al., 2002b). Cronbach's alpha for the asset constructs ranged from .61 to .81.

The nine assets (listed with the number of items representing each asset, Cronbach's alpha, and an example item) are:

- Non-Parental Adult Role Models (seven items, .74, "You know adults that encourage you often.");

- Peer Role Models (six items, .81, "Are most of your friends responsible?"); Family Communication (four items, .61, "How often do you talk to an adult in your household about your problems?");

- Use of Time (groups/sports) (four items, .71, "You participate in an organized activity after class.");

- Use of Time (religion) (two items, .71, "How often do you participate in church or religious activities?");

- Community Involvement (six items, .78, "You work to make your community a better place.");

- $\quad$ Aspirations for the Future (two items, .67, "As you look to your future, how important is it to you that you stay in school?");

- Responsible Choices (six items, .69, "You can say no to activities that you think are wrong."); and

- Good Health Practices (exercise and nutrition) (one item, "You take good care of your body by eating well and exercising."). Good Health Practices (exercise and nutrition) was measured with a single item because no two items loaded for this scale in the factor analyses.

Assets were reported as present (1) or absent (0) on the basis of youth mean responses to the items included in the asset scale. Items comprising each scale were generally scored from 1 to 4 ( 4 being the most positive response) and youth were said to have the asset if their mean score was 3 or higher. This indicated that the youth generally answered the asset questions by responding "usually or almost always," "very important or extremely important," and/or "agree or strongly agree." (Oman, Vesely, et al., 2002b). A full description of the development and construction of the assets is published elsewhere (Oman, Vesely, et al., 2002b).

\section{Sexual Activity}

Sexual activity was assessed with the item. "Have you ever had sexual intercourse ('done it', 'had sex', 'made love', 'gone all the way')?" Youth responded either "yes" (coded 0) or "no" (coded 1) to the item. The item is provided and recommended by the authors of the Prevention Minimum Evaluation Data Set (Brindis, Peterson, Card, \& Eisen, 1998).

\section{Statistical Analysis}

Of 1350 youth in the primary study, 255 (19\%) youth reported their race/ethnicity as Hispanic or Latino. Our analysis had a sample size of 232 after excluding 23 youth due to missing data (12 parental income, 9 sexual intercourse questions, 2 missing both). All statistical analyses were performed with SPSS for Windows, Release 10.0 (SPSS, 1999). An alpha of 0.05 was used to determine statistical significance. Bivariate associations between the dichotomous risk factor and the demographic variables were assessed using a chi-square test. The unadjusted odds ratios (OR) between each asset and the absence of the risk factor (i.e., never had sexual intercourse) were calculated using logistic regression. Individual multiple logistic regression 
analyses were performed to examine the relationship between the absence of the risk factor and each asset while adjusting for the possible confounders of age, gender, and family structure.

Potential interactions between each asset and age, gender, and family structure were assessed in each logistic regression. In order to decrease the risk of Type I error, the alpha level was set at 0.01 to evaluate the interactions. We also conducted multiple logistic regression to determine if the assets were significantly associated with the absence of the risk factor in the presence of other assets. Age, gender, and family structure, since they were potential confounders, were controlled for, and all assets that maintained a $p$-value $\leq 0.05$ were included in the final model. Interactions between the assets and the demographic variables were assessed using a $\mathrm{p}$-value of $\leq 0.01$ and an interaction term was added to the final model when appropriate.

\section{Results}

\section{Descriptive Data}

The mean age of the Hispanic youth sample was $15.4( \pm 1.7)$ years; $50 \%$ of the sample was female. Approximately $58 \%$ of the youth lived in two-parent households and $84 \%$ lived in households with reported income levels of less than $\$ 35,000$. For $40 \%$ of the youth, neither parent had graduated from high school. Of the 232 youth in the study, 149 youth $(64 \%)$ reported never having had sexual intercourse. More females (69\%) than males (60\%) reported that they never had sexual intercourse. Other descriptive data are reported in Table 1.

Table 1

Frequencies and Chi-Square Values for Youth and Parent Demographics And Never had Sexual Intercourse for Hispanics and Latinos $(n=232)$

\begin{tabular}{|c|c|c|c|}
\hline & & & P-Value ${ }^{a}$ \\
\hline & No. & $\begin{array}{l}\% \text { Never Had Sexual } \\
\text { Intercourse }\end{array}$ & \\
\hline Youth Age & & & $<0.001$ \\
\hline $13-14$ & 8 & $87.7^{1}$ & \\
\hline $15-17$ & 120 & 56.7 & \\
\hline $18-19$ & 31 & 32.3 & \\
\hline Youth Gender & & & 0.159 \\
\hline Female & 115 & 68.7 & \\
\hline Male & 117 & 59.8 & \\
\hline Parent Income & & & 0.960 \\
\hline$<20 \mathrm{~K}$ & 96 & 64.6 & \\
\hline $20-35 K$ & 99 & 64.6 & \\
\hline$>35 \mathrm{~K}$ & 37 & 62.2 & \\
\hline Family Structure & & & 0.080 \\
\hline 2 Parent household & 135 & 68.9 & \\
\hline 1 Parent household & 97 & 57.7 & \\
\hline Parent Education & & & 0.780 \\
\hline$<$ High School, both parents & 93 & 66.7 & \\
\hline $\begin{array}{l}1 \text { parent had high school, GED } \\
\text { or some college }\end{array}$ & 127 & 62.2 & \\
\hline $\begin{array}{l}\text { At least one parent had } \\
\text { bachelor's degree or higher }\end{array}$ & 12 & 66.7 & \\
\hline
\end{tabular}

\footnotetext{
${ }^{a}$ Chi-square test of independence ${ }^{1}$ Significant trend $(p<0.05)$
} 
The only significant difference in demographic variables was noted for age. As the youth age increased, the proportion reporting never having had sexual intercourse decreased significantly, from $88 \%$ for young teens, ages $13-14$, to $57 \%$ for middle teens, ages $15-17$, dropping to $32 \%$ for older youth, ages 18-19. There was no significant difference related to gender, family structure, parental education, or parental income for this outcome.

\section{Youth Assets}

Proportions of Hispanic youth with each of nine assets are presented in Table 2. The least prevalent asset was Community Involvement, which $9 \%$ of the youth reported, followed by Use of Time (groups/sports) reported by $26 \%$ of the youth. The most prevalent asset was

Responsible Choices, which $85 \%$ of the youth reported, followed by Aspirations for the Future, which was reported by $83 \%$ of the youth.

Table 2

Percent of Youth with Each of the Nine Assets

\begin{tabular}{|l|l|l|}
\hline Asset & N & $\begin{array}{l}\% \text { who have } \\
\text { asset }\end{array}$ \\
\hline Non-Parental Adult Role Model & 205 & 69.3 \\
\hline Peer Role Models & 230 & 47.4 \\
\hline Family Communication & 232 & 53.4 \\
\hline Use of Time (Groups/Sports) & 230 & 26.1 \\
\hline Use of Time (Religion) & 232 & 46.1 \\
\hline $\begin{array}{l}\text { Good Health Practices } \\
\text { (Exercise/Nutrition) }\end{array}$ & 231 & 67.5 \\
\hline Community Involvement & 231 & 8.7 \\
\hline Future Aspirations & 205 & 83.4 \\
\hline Responsible Choices & 232 & 84.5 \\
\hline
\end{tabular}

\section{Assets and Youth Sexual Risk Behaviors}

As shown in Table 3, the odds of never having had sexual intercourse was over three times higher for Hispanic youth with the Peer Role Models asset as compared to Hispanic youth without this asset (odds ratio $(O R)=3.17)$. This association was also observed for youth with the Responsible Choices asset $(\mathrm{OR}=3.19)$. For Hispanic youth with the Use of Time (Religion) asset, the odds of never having had sexual intercourse were over five and one-half times higher compared to Hispanic youth without that asset. 
Table 3

Youth Assets on Adolescent Never Had Sexual Intercourse

Unadjusted and Adjusted Odds Ratios (OR) with 95\% Confidence Intervals (CI) from Individual Multiple Logistic Regression Models

\begin{tabular}{|l|c|c|c|c|c|}
\hline Youth Asset & & \multicolumn{2}{|c|}{ Unadjusted } & \multicolumn{2}{c|}{ Adjusted $^{\mathrm{a}}$} \\
\hline & $\mathrm{N}$ & OR & $95 \% \mathrm{CI}$ & OR & $95 \% \mathrm{CI}$ \\
\hline Non-Parental Adult Role Model & 205 & 1.57 & $(0.84,2.94)$ & 1.78 & $(0.89,3.56)$ \\
\hline Peer Role Models & 230 & $2.99 *$ & $(1.69,5.30)$ & $3.17 *$ & $(1.67,6.02)$ \\
\hline Family Communication & 232 & 1.29 & $(0.75,2.21)$ & 1.16 & $(0.64,2.11)$ \\
\hline Use of Time (Groups/Sports) & 230 & 1.30 & $(0.70,2.44)$ & 1.25 & $(0.63,2.49)$ \\
\hline Use of Time (Religion) & 232 & $4.42^{*}$ & $(2.43,8.05)$ & $5.61^{*}$ & $(2.80,11.27)$ \\
\hline $\begin{array}{l}\text { Good Health Practices } \\
\text { (Exercise/Nutrition) }\end{array}$ & 231 & 1.00 & $(0.57,1.78)$ & 0.94 & $(0.49,1.82)$ \\
\hline Community Involvement & 231 & 1.76 & $(0.62,5.03)$ & 2.14 & $(0.64,7.08)$ \\
\hline Future Aspirations & 205 & 1.25 & $(0.58,2.71)$ & 1.46 & $(0.62,3.42)$ \\
\hline Responsible Choices & 232 & 2.02 & $(0.98,4.13)$ & $3.19^{*}$ & $(1.40,7.28)$ \\
\hline
\end{tabular}

${ }^{a}$ Adjusted for youth age and gender, and family structure

$* P \leq 0.05$

Table 4 shows the final logistic regression model that includes all significant assets. The Peer Role Models and Use of Time (Religion) assets were both significant in the model after controlling for demographic variables. For example, the odds of never having had sex are over five times greater for youth who report having the Use of Time (religion) asset as compared with a youth without the asset after taking into account the demographic variables and the Peer Role Models asset. This result suggests that the Peer Role Models and Use of Time (religion) assets are each independently related to never having had sexual intercourse.

Table 4

Adjusted Odds Ratios (OR) with 95\% Confidence Intervals (CI) from Multiple Logistic Regression Model for Hispanic Youth on Adolescent Never Had Sexual Intercourse

\begin{tabular}{|l|c|c|c|}
\hline & & \multicolumn{2}{|c|}{ Adjusted $^{\mathrm{a}}$} \\
\hline & $\mathrm{N}$ & $\mathrm{OR}$ & $95 \% \mathrm{CI}$ \\
\hline Peer Role Models & 230 & & \\
\hline Use of Time (Religion) & & $2.61^{*}$ & $(1.33,5.14)$ \\
\hline \multicolumn{2}{|l|}{ Likelihood ratio test ${ }^{\mathrm{b}} \mathrm{X}^{2}=36.308, \mathrm{df}=2, \mathrm{p}<0.0001$} & $5.24 *$ & $(2.55,10.78)$ \\
\hline \multicolumn{2}{|l|}{ Hosmer and Lemeshow Goodness-of-Fit Test $\mathrm{X}^{2}=3.463, \mathrm{df}=8, \mathrm{p}=0.902$} \\
\hline
\end{tabular}

${ }^{a}$ Adjusted for youth age and race, family structure, and other variables in the model

${ }^{\mathrm{b}}$ Comparing the model with demographic variables only to model with demographic variables and assets

$* \mathrm{P} \leq .05$

\section{Discussion}

This study is among the first to examine associations between specific youth assets and sexual intercourse in Hispanic youth. The results indicated that the odds of never having had sexual intercourse were at least three times higher for Hispanic youth with the Peer Role Models, Use of Time (religion), or Responsible Choices assets, compared to Hispanic youth without any one 
of these assets. The final analytic model indicated that the Peer Role Models and Use of Time (religion) assets were each independently related to never having had sexual intercourse but the influence of the Responsible Choices asset was diminished to being nonsignificant.

The relationships between each asset (i.e., Use of Time (religion), Responsible Choices and Peer Role Models) and youth sexual behavior in the present analyses were similar to those for all races noted in a previous analysis of these data that included youth of all races (Vesely et al., 2004). For Hispanic youth, however, the effects were magnified in that odds ratios were larger for Hispanic youth compared to youth of all races for the Peer Role Models, Responsible Choices, and Use of Time (Religion) assets. These analyses also found differences from the previous study. For example, some assets (i.e., Non-Parent Adult Role Models, Aspirations for the Future, Community Involvement, and Family Communication) were associated with abstinence for all race/ethnicity but not for Hispanic youth. However, since the point estimates in the odds ratios in the Hispanic samples are similar in magnitude to those found in the analyses of the combined race/ethnicity study, the smaller sample size may be the reason these assets were not statistically significant in the present study.

\section{Peer Role Models}

If these assets are protective from sexual activity for Hispanic youth, the mechanisms of action should be explored. For the Peer Role Model asset, evidence suggests that adolescents often influence each other positively, by either modeling behaviors or pressuring each other to behave in certain ways or adopt certain attitudes or goals. Decisions about initiation are strongly bound to social context, with peers playing an important role in creating a sense of normative behavior. Specific components of peer norms impact the process of sexual initiation in both positive and negative ways, with research suggesting that peer relationships perpetuate adolescents' behaviors -- positive reinforcing positive and negative reinforcing negative (Kinsman, Romer, Furstenberg, \& Schwarz, 1998; Moore \& Zaff, 2002).

At all levels of peer context, the strongest and largely protective effects for girls are having lowrisk friends, with a female's close group of friends having the most influence on sexual debut. Additionally for girls, how close a girl's friends are to their parents appeared as important as a girl's relationship with her own parents (Bearman \& Bucker, 1999). As might be expected, having high-risk male friends increased pregnancy risk for girls (Bearman \& Bucker, 1999). When factors of family structure, wealth, education and popularity were controlled, adolescents whose friendship network included mostly low-risk friends were half as likely to experience first intercourse as were adolescents whose close friend network was composed mostly of high-risk friends (Sieving, Eisenberg, Pettingell, \& Skay, 2006).

\section{Use of Time (Religion)}

The findings related to the Use of Time (religion) asset are important as the influence of spirituality, religiosity, and involvement of religious activity is an area of growing interest, which has had limited research. Several studies involving different adolescent ages and developmental stages show that religion and/or involvement in religious activities appears to be a protective factor throughout the teen years (Catalano, Berlund, Ryan, Lonszak,\& Hawkins, 2002; Holder et al., 2000; Nonnemaker, McNeely, \& Blum 2003; Rostosky, Regenerus, \& Wright, 2003). In a study of younger teens, ages 11-15, respondents who were not sexually active scored significantly higher than sexually active youth on the importance of religion in their lives and reported more connections to friends whom they considered to be religious or spiritual (Holder et al., 2000). 


\section{Responsible Choices}

Teens say morals, values, and/or religious beliefs influence their decisions about sex more than parents, concerns about pregnancy and sexually transmitted diseases, friends, teacher and sexual educators, or the media (Kirby \& Troccoli, 2003). A national survey of 15-19 year olds in 2002 indicated that males and females chose the same main reason why they had not yet had sexual intercourse, both citing it was "against religion or morals", $31.4 \%$ and $37.8 \%$ respectively (Abma, Martinez, Mosher, \& Dawson, 2004).

Likewise, religiosity has been identified as one factor that appears to be associated with delaying sexual intercourse among males (Marsiglio, Vastine Ries, Sonenstein, Troccoli, \& Whitehead, 2006). The lack of religious involvement was identified as part of a cluster of antecedents to teen pregnancy in a major research review of "reasons why" teens became sexually active. That study noted that both religiosity and an attachment to religious institutions were protective factors for some sexual behaviors, such as initiation of sex and number of sex partners (Kirby, 1999). In another study, key distal protective factors included church attendance (Jessor, Turbin, \& Costa, 1998).

A summary of 50 studies found support for the idea that religiosity (variously defined) was associated with delayed sexual activity among some groups of teens (DaFoe Whitehead, Wilcox, \& Scales Rostoskey, 2001). However, that report also noted the poor state of research in this area, limiting conclusions that could be drawn.

\section{Potential Protective Asset}

It is interesting to note that the prevalence of some assets was quite low in this sample of Hispanic youth, particularly, the Community Involvement asset, with only $9 \%$ reporting the presence of that asset. Research studies have begun to identify this asset, and programs that include extensive structured voluntary service in the community, as showing clear evidence among the general teen population that they reduce pregnancy rates while youth are in the programs (Kirby, 2001). This emerging research may prove to be an important area for future study to determine its potential for strengthening programs that seek to reduce adolescent risk behaviors among Hispanic youth.

\section{Limitations}

There are limitations to this study. Youth may have provided inaccurate, socially acceptable responses to the risk behavior questions even though they were allowed to read the questions and enter their responses into a computer unobserved. This protocol may have reduced the number of socially acceptable responses. Also, the moderate response rate raises questions about the generalizability of the results.

Further research is necessary to determine if the results are due to sample size issues, social or cultural norms or to actual race/ethnicity differences. Studies with larger sample sizes and longitudinal study designs will greatly increase our understanding of the relationships among assets in Hispanic youth and sexual and related risk behaviors. When considering the applicability of these results to other settings, it is important to remember that teen birth rates vary among Hispanic subgroups based on the country of origin, generational status, and acculturation of the particular population. The majority of Hispanic residents in the area where this study was conducted are Mexican-Americans. Finally, the data analyzed in this study are cross-sectional. An asset/risk behavior causal relationship cannot be tested. 


\section{Conclusion}

This study represents an initial effort to explore the relationship between youth assets and sexual intercourse among Hispanic/Latino youth. The study found three assets - Use of Time (religion), Peer Role Models, and Responsible Choices -- that appeared protective for sexual intercourse compared to the youth without these assets. Compared to the larger study of all racial groups, the relationships between these assets and sexual behavior were larger although fewer assets overall were related to sexual behavior in the Hispanic sample.

With Hispanics representing the highest teen birth rate of any racial or ethnic group, and given the projected population increase for Hispanic teens and large percentage of Hispanic youth living in poverty, there is an immediate need to identify and implement strategies that reduce sexual risk behaviors.

The findings of this study provide interesting and timely implications for informing program and policy development at the community, state, and national levels. The findings support the need to incorporate strategies for increasing specific youth assets as part of efforts to reduce adolescent sexual health risk behaviors among Hispanics. Additional research is needed to better understand the potential influence of these assets on sexual activity among Hispanic youth, that will result in more effective and culturally appropriate prevention programs tailored to the needs of and protective factors found in that population.

\section{References}

Abma, J.C., Martinez, G.M., Mosher, W.D., \& Dawson, B.S. (2004). Teenagers in the United States: Sexual activity, contraceptive use, and childbearing, 2002. Vital Health Statistics, 23(24), 2.

Beal, A.C., Ausiello, J., \& Perrin, J.M. (2001). Social influences on health-risk behaviors among minority middle school students. Journal of Adolescent Health, 28(6), 474-480.

Bearman, P.S., \& Bucker, H. (1999). Power in numbers: Peer effects on adolescent girls' sexual debut and pregnancy. Washington, DC: National Campaign to Prevent Teen Pregnancy.

Benard, B. (1990). Youth service: From youth as problems to youth as resources. Prevention Forum, January, 6-14.

Bogenschneider, K. (1996). An ecological risk/protective theory for building prevention programs, policies, and community capacity to support youth. Family Relations, 45, 127-138.

Brindis, C., Peterson, L.J., Card, J.J., \& Eisen, M. (1998). Prevention Minimum Evaluation Data Set (PMEDS): A minimum data set for evaluating programs aimed at preventing adolescent pregnancy and STD/AIDS. Los Altos, CA: Sociometrics Corporation.

Catalano, R.F., Berglund, M.L., Ryan, J.A., Lonczak, H.S., \& Hawkins, J.D. (1998). Positive youth development in the United States. From http://aspe.hhs.gov/hsp/PositiveYouthDev99/

Centers for Disease Control and Prevention. (2001). HIV/AIDS surveillance report (No. 13(2)). Atlanta: Centers for Disease Control and Prevention. 
DaFoe Whitehead, B., Wilcox, B., \& Scales Rostoskey, S. (2001). Keeping the faith: The role of religion and faith communities in preventing teen pregnancy. Washington DC: National Campaign to Prevent Teen Pregnancy.

Day, J.C. (1996). Population projections of the United States by age, sex, race, and Hispanic origin: 1995 to 2050: U.S. Census Bureau.

DiIorio, C., Kelley, M., \& Hockenberry-Eaton, M. (1999). Communication about sexual issues: Mothers, fathers, and friends. Journal of Adolescent Health, 24(3), 181-189.

Driscoll, A.K., Biggs, M., Brindis, C.D., \& Yankah, E. (2001). Adolescent Latino reproductive health: A review of the literature. Hispanic Journal of Behavioral Sciences,23(3), 255-326.

Driscoll, A.K., Brindis, C.D., Biggs, A., \& Valderrama, T. (2004). Priorities, progress and promise: A chartbook on Latino adolescent reproductive health. San Francisco, CA: University of California.

Hamilton, B.E., Martin, J.A., \& Sutton, P.D. (2003). Births: Preliminary data for 2002, 51(11). National Vital Statistics Reports(April 1st, 2006).

Hamilton, B.E., Ventura, S.J., Martin, J.A., \& Sutton, P.D. (2005). Preliminary births for 2004. Retrieved April 15th, 2006, from http://www.cdc.gov/nchs/products/pubs/pubd/hestats/prelim births/prelim births04.htm

Holder, D.W., Durant, R.H., Harris, T.L., Daniel, J.H., Obeidallah, D., \& Goodman, E. (2000). The association between adolescent sexual spirituality and voluntary sexual activity. Journal of Adolescent Health, 26(4), 295-302.

Jessor, R.J. (1991). Risk behaviors in adolescence: A psychosocial framework for understanding and action. Journal of Adolescent Health, 12(8), 597-605.

Jessor, R.J., Turbin, M.S., \& Costa, F.M. (1998). Protective factors in adolescent health behavior. Journal of Personality and Social Psychology, 75(3), 788-800.

Kinsman, S., Romer, D., Furstenberg, F.F., Jr., \& Schwarz, D. (1998). Early sexual initiation: The role of peer norms. Pediatrics, 105(5), 1185-1192.

Kirby, D. (1999). Looking for reasons why: The antecedents of adolescent sexual risk-taking, pregnancy, and childbearing. Washington DC: National Campaign to Prevent Teen Pregnancy.

Kirby, D. (2001). Emerging answers: Research findings on programs to reduce teen pregnancy. Washington, DC: National Campaign to Prevent Teen Pregnancy.

Kirby, D., Short, L., Collins, J., Rugg, D., Kolbe, L., Howard, M., et al. (1994). School-based programs to reduce sexual risk behavior: A review of effectiveness. Public Health Reports, 109, 339-360.

Kirby, D., \& Troccoli, K. (2003). Progress pending: How to sustain and extend recent reductions in teen pregnancy rates. Washington DC: National Campaign to Prevent Teen Pregnancy. 
Leffert, N., Benson, P.L., Scales, P.C., Sharma, A.R., Drake, D.R., Blyth, D.A. (1998).

Developmental assets: Measurement and prediction of risk behaviors among adolescents. Applied Developmental Science, 2(4), 209-230.

Longmore, M.A., Manning, W.D., \& Giordano, P.C. (2001). Preadolescent parenting strategies and teens' dating and sexual initiation: A longitudinal analysis. Journal of Marriage \& the Family, $63(2), 322-335$.

Marsiglio, W., Vastine Ries, A., Sonenstein, F., Troccoli, K., \& Whitehead, M. (2006). It's a guy thing: Boys, young men, and teen pregnancy prevention. Washington DC: National Campaign to Prevent Teen Pregnancy.

Martin, J.A., Hamilton, B.E., Sutton, P.D., Ventura, S.J., Menacker, F., \& Munson, M.L. (2005). Births: Final data for 2003. National Vital Statistics Reports, 54(2) Retrieved April 1st, 2006.

McKnight, J.L. (1997). A 21st century map for healthy communities and families. Families in Society, March/April, 117-127.

Moore, K., Peterson, J., \& Furstenberg, F. (1986). Parental attitudes and the occurrence of early sexual-activity. Journal of Marriage and the Family, 48(4), 777-782.

Moore, K., \& Zaff, J.F. (2002). Building a better teenager: A summary of "what works" in adolescent development. Washington DC: Child Trends, Inc.

National Campaign to Prevent Teen Pregnancy. (2006). Science says: Teens' sexual experience, 1995-2002. Washington DC: National Campaign to Prevent Teen Pregnancy.

Oman, R.F., McLeroy, K., Vesely, S., Aspy, C.B., Smith, D.W., \& Penn, D.A. (2002a). An adolescent age group approach to examining youth risk behaviors. American Journal of Health Promotion, 16(3), 167-176.

Oman, R.F., Vesely, S.K., McLeroy, K.R., Harris-Wyatt, V., Aspy, C.B., Rodine, S., et al. (2002b). Reliability and validity of the Youth Asset Survey (YAS). Journal of Adolescent Health, 31(3), 247-255.

Pittman, K., Irby, M., Tolman, J., Yohalem, N., \& Ferber, T. (2003). Preventing problems, promoting development, encouraging engagement: Competing priorities or inseparable goals? Washington DC: The Forum for Youth Investment: Impact Strategies, Inc.

Resnick, M.D., Bearman, P.S., Blum, R.W., Bauman, K.E., Harris, K.M., Jones, J., et al. (1997). Protecting adolescents from harm: Findings from the National Longitudinal Study on Adolescent Health. Journal of the American Medical Association, 278(10), 823-832.

Rodriguez, M., \& Morrobel, D. (2004). A review of Latino youth development research and a call for an asset orientation. Hispanic Journal of Behavioral Sciences 26(2), 107-127.

Rucibwa, N.K., Modeste, N., Montgomery, S., \& Fox, C.A. (2003). Exploring family factors and sexual behaviors in a group of Black and Hispanic adolescent males. American Journal of Health Behavior, 2オ1), 63-74. 
Ryan, S., Franzetta, K., \& Manlove, J. (2005). Hispanic teen pregnancy and birth rates: Looking behind the numbers. Child Trends Research Brief Retrieved November 2005, from http://www.childtrends.org/Files/HispanicRB.pdf

Scales, C.P., \& Leffert, N. (1999). Developmental assets: A synthesis of the scientific research on adolescent development. Minneapolis, MN: Search Institute.

Scales, P.C. (1990). Developing capable young people: An alternative strategy for prevention programs. Journal of Early Adolescence, 10, 420-438.

Sieving, R.E., Eisenberg, M.E., Pettingell, S., \& Skay, C. (2006). Friends' influence on adolescents' first sexual intercourse. Perspectives on Sexual \& Reproductive Health, 38(1), 1319.

SPSS. (1999). SPSS Base 10.0 Applications Guide. Chicago, IL: SPSS.

U. S. Census Bureau. (2001). Population by sex, age, Hispanic origin, and race: March 2000. Retrieved March 31st, 2006, from www.census.gov/population/socdemo/hispanic/p20535/tab01-3.txt

U. S. Census Bureau. (2002). Statistical abstract of the United States. Retrieved March 31st, 2006, from http://www.census.gov/statab/www/

U.S. Census Bureau. (2004). U.S. interim projections by age, sex, race, and Hispanic origin. Retrieved December 7, 2004, from http://www.census.gov/ipc/www/usinterimproj/

Velez-Pastrana, M.C., Gonzalez-Rodriguez, R.A., \& Borges-Hernandez, A. (2005). Family functioning and early onset of sexual intercourse in Latino adolescents. Adolescence, 40(160), 777-791.

Vesely, S., Wyatt, V.H., Oman, R.F., Aspy, C.B., Kegler, M., Rodine, S., et al. (2004). The potential protective effects of youth assets from adolescent sexual risk behaviors. Journal of Adolescent Health, 34, 356-365.

Acknowledgments: This project was supported under a cooperative agreement from the Centers for Disease Control and Prevention (CDC) through the Association of Schools of Public Health (ASPH) Grant Number U36/CCU300430. The contents of this article are solely the responsibility of the authors and do not necessarily represent the official views of CDC or ASPH.

(C) Copyright of Journal of Youth Development Bridging Research and Practice. Content may not be copied or emailed to multiple sites or posted to a listserv without copyright holder's express written permission. However, users may print, download or email articles for individual use. 